\title{
Antecedents and Consequences of System Justification Among Iranian Migrants in Western Europe
}

\author{
Maarten Johannes van Bezouw ${ }^{1}$, Jojanneke van der Toorn ${ }^{2,3}$, Ali Honari ${ }^{4}$, Arieke J. Rijken ${ }^{5}$ \\ [1] University of Amsterdam, Amsterdam, The Netherlands. [2] Utrecht University, Utrecht, The Netherlands. [3] Leiden University, Leiden, The Netherlands. \\ [4] Vrije Universiteit Amsterdam, Amsterdam, The Netherlands. [5] Netherlands Interdisciplinary Demographic Institute, The Hague, The Netherlands.
}

Journal of Social and Political Psychology, 2021, Vol. 9(2), 637-653, https://doi.org/10.5964/jspp.5445

Received: 2020-12-14 • Accepted: 2021-08-26 • Published (VoR): 2021-12-07

Handling Editor: Hélder Vinagreiro Alves, Centro de Investigação e Intervenção social, ISCTE-IUL, Lisbon, Portugal

Corresponding Author: Maarten Johannes van Bezouw, Department of Work and Organizational Psychology, University of Amsterdam, Nieuwe Achtergracht 129, 1018 WS, Amsterdam, The Netherlands. E-mail: m.j.vanbezouw@uva.nl

Supplementary Materials: Materials [see Index of Supplementary Materials]

\begin{abstract}
Seeing the sociopolitical system as fair and legitimate is important for people's participation in civic duties, political action, and the functioning of society in general. However, little is known about when migrants, without life-long socialization in a certain system, justify the sociopolitical system of their host country and how system justification influences their political participation. We examined antecedents of system justification using a survey among Iranian migrants in eight European countries $(\mathrm{N}=935)$. Subsequently, we examined the relationship between system justification and political participation intentions. We found that system justification beliefs are generally high in our sample, mainly stemming from an assessment of opportunity to achieve changes in intergroup relations. Stronger social identity threat, feeling disadvantaged, a longer residence in Europe, and perceived intergroup stability all relate to less system justification. Conversely, stronger efficacy beliefs bolster system justification. Furthermore, we found some support for a curvilinear relationship between system justification and political participation intentions, but the size of this effect is small. The results show that the high levels of system justification of Iranian migrants are at risk when discrimination and disadvantage are perceived to be stable facets of society. Surprisingly, political participation to better Iranian migrants' societal position is barely affected by system justification. We discuss implications and further research that can increase understanding of system justification among migrants.
\end{abstract}

\section{Keywords}

system justification theory, Iranian migrants, political participation, migration

\section{Non-Technical Summary}

\section{Background}

It is important for society that citizens see its social and political system as fair. People are more likely to be active members of society when they think that institutions, policies, and the relations between various groups in a country are legitimate and fair. In an increasingly globalized world, migrants are part of societies worldwide. For migrants who did not grow up in a certain system, there might be specific reasons to see the system as unfair or fair. 


\section{Why was this study done?}

The reasons why migrants find the social and political system of the country they migrated to unfair or fair are mostly unknown. We thought it would be important to get to know these reasons to better understand possible barriers for migrants to experiencing a fair system and engage actively in society. We also wanted to know whether fairness of the system was related to participation in political actions such as street demonstrations.

\section{What did the researchers do and find?}

We examined which factors make Iranian migrants see the social and political system as fair in their European country of residence. We asked Iranian migrants living in one of eight Western European countries to complete an online questionnaire. In the questionnaire, we asked their perceptions of the system. We also assessed how willing they were to engage in political actions. We found that Iranian migrants generally thought that the system was fair. However, being discriminated against, feeling disadvantaged, and feeling that relations between groups in society could not be changed were all linked with seeing the system as more unfair. Also, migrants who lived in Europe longer thought that the system was less fair compared to those who migrated recently. Political action was not strongly affected by whether the system was seen as fair or not, but there is some suggestion that a moderate support for the system might make political action more likely.

\section{What do these findings mean?}

Our findings highlight that migrants indeed have specific reasons to see the system as fair or unfair. For Iranian migrants, it seemed to be important to have opportunities in society, without facing discrimination. It is possible that for other migrant groups, different factors play a bigger role in whether the system is seen as legitimate. Taken together, our findings highlight the importance of studying these various factors in order to understand the reasons why a social and political system is seen as fair and legitimate by all members of society.

Migrating to another country involves a complex psychological change and adaptation process to get used to a new social and political reality. While migration may help in escaping adverse conditions in the country of origin, it often entails becoming a minority in the new country of settlement. It might provide new opportunities for work or studies, while at the same time causing new threats and challenges associated with being a migrant. In this article, we examine how Iranian migrants ${ }^{1}$ in Western Europe relate to their host country's sociopolitical system. Believing that the government is legitimate, but also that other institutions and citizens can be trusted is crucial for the functioning of any society (e.g., Newton, Stolle, \& Zmerli, 1999). For people experiencing radical changes caused by migrating from one country to another, questions about the legitimacy and fairness of the social and political system are especially salient. Moreover, having at least some confidence in a sociopolitical system might be needed for migrants to better their group's position in society through political action, such as voting or joining a street demonstration. In a survey among Iranian migrants in eight Western European countries, we asked how long they have been part of this new system, what opportunities and threats they experience in this system, and how they identify with their ethnic ingroup and the native population of the country. We investigated how these variables are related to their levels of system justification (Jost \& Banaji, 1994). Subsequently, we assessed how their system justification motivation shapes intentions to engage in political action to improve the societal position of Iranian migrants.

System justification theory is an influential theory about people's attitudes toward the social and political system (Jost \& Banaji, 1994). This system refers to current social, economic, and political arrangements (Jost \& Van der Toorn, 2012). System justification theory posits that people derive a sense of security, safety and shared reality from believing that the social and political system they are part of is fair and just (e.g., Jost, Banaji, \& Nosek, 2004). Thus, because of these psychological needs, people may be motivated to inflate the fairness of a system, even when that system is not

1) We use the term "migrant" as an umbrella term for a person either temporarily or permanently residing in another country than the country of birth. The term "immigrant", commonly used when residence outside the country of birth is permanent, is used only when citing specific literature on immigrants rather than migrants. 
ideal. In accordance with this motivated account of system justification, experimental evidence has shown that people justify the system more when it is criticized (Lau, Kay, \& Spencer, 2008), or when one's powerlessness within the system is highlighted (Van der Toorn et al., 2015). As such, justification of the system can restore a sense of security and fairness. However, while people might be generally motivated to perceive the system as fairer than it is, attitudes about the system are also influenced by social realities - for example the position one has in society.

Perceptions of the fairness of a social and political system, we argue, are the result of an ongoing evaluation process. Does a sense of fairness need to be restored when there are threats to the system? Who is to blame for flaws in the system? We follow Cichocka, Górska, Jost, Sutton, and Bilewicz (2018) in arguing that a measurement of system justification can provide insight into people's current perceptions of fairness of the social and political system. These current perceptions can be the outcome of a motivated process of restoring a sense of fairness (e.g., Henry \& Saul, 2006; Van der Toorn et al., 2015) but might also be influenced by self-interest and ingroup interest (see Jost, Pelham, Sheldon, \& Sullivan, 2003) that could dampen the strength of system justification. People might, for example, blame the system for their ingroup's disadvantaged position to protect the image of the ingroup. Possibly because of these different - and sometimes competing - motivations, the extent to which people see the system as fair and why they think so is difficult to assess.

Limited opportunities for work, experiences of discrimination, and contrasts between the new system and the system of origin (e.g., Verkuyten, 2006) might make migrants' relation to the system different compared to native inhabitants of a country. Given the challenges migrants face, they might be particularly negative about the system. Conversely, especially when migration is motivated by seeking a more prosperous or democratic place to live, contrasting the host nation with the country of origin may increase system justification among migrants. To our knowledge, system justification motivation has not been studied among migrants. In this research, we investigate multiple predictors of system justification among Iranian migrants in Western Europe, drawing from the literatures on system justification, acculturation, and intergroup relations. We equate 'the system' broadly to the social, political, and cultural aspects of the European country that Iranian migrants currently live in.

\section{Iranian Migration to Western Europe}

The Iranian revolution of 1978-1979 spurred large-scale migration of Iranian nationals mainly to the United States of America, Canada, and various countries in Europe (Ghorashi \& Boersma, 2009). At first, those who fled Iran were mainly people loyal to the ousted Pahlavi regime but later waves of emigration from Iran were formed by political activists who opposed the revolutionary regime, ethnic and religious minorities, and citizens who fled from the Iran-Iraq war that started in 1980 (Ghorashi, 2003; Lewin, 2001). In subsequent decades, highly educated people were especially likely to leave Iran for Western countries to pursue further education or seek new job opportunities. This amounted to the highest rate of elite emigration ("brain-drain") among underdeveloped or developing countries (e.g., Morady, 2011).

In Western Europe, Iranian migrants are comparatively advantaged vis-à-vis other non-Western migrants in terms of educational level, often holding university degrees (e.g., Kelly \& Hedman, 2016). At the same time, Iranian migrants regularly face problems obtaining meaningful employment and high unemployment rates have contributed to onward migration to other Western countries within and outside of Europe (Kelly \& Hedman, 2016). In this research, we examine how this seemingly ambiguous position of Iranian migrants - being highly educated but also facing difficulties due to being migrants - influences the strength of system justification.

\section{Antecedents of System Justification for Migrants}

The causes and consequences of system justification have been studied in various contexts and among different social groups (e.g., Jost, Pelham, et al., 2003). However, all these studies hitherto have focused on people growing up in, or being long-term members of, a certain system. This is not the case for recent migrants, who might therefore relate differently to the system. We therefore examine known predictors of system justification, such as political orientation, as well as predictors that are expected to be relevant specifically for migrants. 


\section{Political Orientation}

According to Jost, Glaser, Kruglanski, and Sulloway (2003), political conservatism is a form of system justification and indeed the positive relation between conservatism and system justification has often been demonstrated (see Jost et al., 2017 for an overview). The political orientation of Iranian migrants is marked by 'forced' migration (Ghorashi, 2003) after different pivotal political moments in Iran over the last decades (Behrooz, 2012). Left- and right-wing political orientation could, therefore, have a different meaning for Iranian migrants compared to a Western perspective, and influence attitudes towards the system differently. However, because we focus on justification of the system of the new country of residence, we expect that stronger right-wing political orientation is associated with increased justification of the system (in line with Jost et al., 2017).

\section{Perceived Opportunities: Societal Stability and Political Efficacy}

Stable systems -for example when inequality in society is enduring - are more likely to be justified (Laurin, Gaucher, \& Kay, 2013). This finding suggests that when certain aspects of the system are seen as inevitable, people have a stronger motivation to justify the status quo. We argue that the absence of social mobility is an important marker of stability in society. However, Day and Fiske (2017) have shown that Americans show stronger endorsement of the system when they are exposed to moderate as opposed to low social mobility frames, suggesting that some instability might be associated with more system support. Especially for higher educated Iranians migrating to Western-Europe, the new country of residence could primarily be seen as an opportunity for social mobility (e.g., Kelly \& Hedman, 2016). We think that Iranian migrants see possibilities for changes in intergroup relations in society as markers for social mobility, and we therefore expect the perception of unstable intergroup relations to increase system justification.

In addition to opportunities for social mobility, being able to influence political decision-making is expected to contribute to believing that the sociopolitical system is fair. Osborne, Yogeeswaran, and Sibley (2015) show that perceived political efficacy of the Maori minority in New Zealand is related to increased perceived system fairness. For Iranian migrants, engagement in politics in Western Europe is different from engagement in Iran. In Iran, protest is often subject to government repression (e.g., Honari, 2018), and increased political efficacy in these repressive contexts might stem from being able to fight against this repression (Ayanian \& Tausch, 2016) and might thus relate to lower levels of system justification. When government repression is less salient - in Europe compared to Iran - we expect, however, that increased political efficacy is related to stronger fairness perceptions of the social and political system.

\section{Discrimination and Relative Deprivation}

Being a migrant entails increased experiences of social identity threat (Verkuyten \& Martinovic, 2012). Social identity threat can consist of being wrongly categorized - being seen as Arab rather than as Iranian for example - or, for instance, being discriminated against in the new society (Branscombe, Ellemers, Spears, \& Doosje, 1999). Additionally, realistic threats such as the difficulties of Iranian migrants to find employment (Kelly \& Hedman, 2016) can create a sense of relative disadvantage among migrants compared to the native majority population.

The extent to which system justification is influenced by the experience of discrimination and disadvantage might depend on who is held accountable. Major, Kaiser, O’Brien, and McCoy (2007) show that Latino Americans only blame being discriminated against on their ingroup, rather than on society, when they believe that one's societal position is the result of one's own efforts. Because many Iranian migrants have difficulties finding meaningful employment despite their high education levels (Kelly \& Hedman, 2016), we expect that the experience of discrimination, threat, and disadvantage is more likely to be ascribed to society; decreasing system justification.

\section{Being Part of the System}

System justification theory posits that people legitimize systems that they are part of (Jost et al., 2004). For Iranian migrants, feeling part of the system might depend on how long they have lived in the host country. Research on political trust, for example, shows that Mexican Americans (Abrajano \& Alvarez, 2010; Michelson, 2003) and immigrants from non-democratic countries in Canada (Bilodeau \& Nevitte, 2003) initially have high levels of political trust which 
decreases over time. Due to contrasting with the Iranian system, we expect recent Iranian migrants to endorse the new system more strongly compared to Iranian migrants who have lived in Western-Europe longer.

People justify systems that they are part of over and above individual- and ingroup interest (Jost et al., 2004). We argue that the respective levels of identification with Europeans and other Iranians could provide insight into the extent that Iranian migrants consider themselves to be part of the new country's society. Wiley (2013) shows that immigrants face the threat of being rejected by the native population, as well as by members of their own ingroup (i.e., other Iranian migrants). Whereas the former may lead to stronger identification with other migrants, the latter might spur stronger identification with the new country (rejection-identification; Wiley, 2013). We expect that stronger identification with native Europeans or with both native Europeans and Iranians, indicating better integration and more investment in the system, is related to increased system justification. Conversely, identification with Iranians is expected to be associated with weaker system justification.

\section{System Justification and Political Participation}

An important reason to examine the strength of system justification is that it provides an assessment of how people relate to the sociopolitical system that they are part of. One marker of citizens' involvement in society is their political participation. Lower rates of voter turnout, or participation in street demonstrations can signal lower trust in political processes, or the perceived illegitimacy of the political elite (e.g., Norris, 2011). Cichocka et al. (2018) have shown that system confidence influences people's political participation, albeit not linearly. Based on several studies conducted in Poland and with World Value survey data from 50 countries worldwide, they show an 'inverted-U' effect: both very low and very high levels of system confidence are associated with reduced political participation (Cichocka et al., 2018). In other words, both those who think that the system is completely unresponsive to their needs and those who think the system functions very well, are less likely to engage in political action. For Iranian migrants, we expect the same logic to apply.

\section{Method}

\section{Data Collection and Procedure}

We used a cross-sectional survey to assess attitudes of Iranian migrants in eight Western European countries with the largest Iranian migrant populations: Austria, Belgium, France, Germany, the Netherlands, the United Kingdom, Sweden, and Switzerland (see the Supplementary Materials for the complete questionnaire). In total, 935 participants completed the questionnaire on the online survey platform Qualtrics. Participation in the questionnaire was completely voluntary and no incentives were given to the participants. The study was approved by the Faculty Ethics Assessment Committee at Utrecht University, the Netherlands. Upon the respondents' choice, the survey was presented in Farsi or in one of the major languages of the European country of residence. Participants who indicated being equally comfortable in one of the native languages and Farsi were randomly allocated to either one of these to prevent possible bias stemming from language of the questionnaire (Barreto, Spears, Ellemers, \& Shahinper, 2003; see Table 1 for the distribution). The questionnaire was translated from the English version by native speakers, and pilot-tested in each country for language comprehensibility.

The data were collected between February and April 2016. The goal was to attract a substantial number of participants in each country, and a post-hoc sensitivity analysis based on 23 predictors (see Table 2 in the Supplementary Materials), test power $=0.80$, alpha level $=0.05, N=935$ ), using GPower software (Faul, Erdfelder, Buchner, \& Lang, 2009), yields a detectable effect size of $f^{2}=0.024\left(R^{2} \approx 0.24\right)$, non-centrality parameter $\lambda=22.54$, and a critical $F$-value $=$ 1.54. We mainly relied on online communities of the Iranian diaspora, which have been shown to be relatively diverse (Ghorashi \& Boersma, 2009; Van den Bos, 2006). The link to the questionnaire was distributed through Facebook groups that were attended by the Iranian diaspora in each country. Other networks and means were used as well, including Twitter and e-mail. Additionally, the study was advertised through a paid banner on one of the biggest websites for the Iranian diaspora worldwide: www.kodoom.com. Each participant was asked to further distribute the survey in 
Table 1

Overview of the Different Versions of the Questionnaire and the Number of Participants per Country

\begin{tabular}{lclc}
\hline Country & $\begin{array}{c}\text { Number of participants } \\
\text { per country }\end{array}$ & Number of participants for each language version \\
\hline Austria & 95 & Farsi (91) & German (4) \\
Belgium & 87 & Farsi (70) & Dutch (13) \\
France & 95 & Farsi (63) & French (32) \\
Germany & 204 & Farsi (167) & German (37) \\
The Netherlands & 166 & Farsi (128) & Dutch (38) \\
The United Kingdom & 107 & Farsi (75) & English (32) \\
Sweden & 114 & Farsi (93) & Swedish (21) \\
Switzerland & 67 & Farsi (55) & German (9) \\
\hline
\end{tabular}

their Iranian diaspora network. We found that $80.7 \%$ of the participants found the questionnaire through Facebook and Twitter, $7.9 \%$ clicked on the advertisement, $6.1 \%$ of the participants received the link to the questionnaire via e-mail, $2.0 \%$ through other ways, and $0.5 \%$ via weblogs.

\section{Sample}

Because we used an online survey with convenience sampling, we provide additional descriptive findings detailing our sample (see Table 2). As expected, younger and higher educated people are over-represented and more men than women participated. The participants by and large indicated that they either could cope or live comfortably on their current income. However, there was still a substantial number of participants indicating it was difficult or very difficult to cope on the current income. Especially in light of the very high level of education, this could indicate some disparity between education level and perceived financial situation for some of the participants in our sample.

Most of the participants had migrated to Western Europe for their studies or for political reasons. These numbers were relatively similar across the eight different countries, although in France a relatively high number of participants indicated migrating for their studies (64.4\%). In the Netherlands (37.3\%) and Belgium (34.9\%), political reasons rather than educational reasons were the most important factor for emigrating from Iran. On average, participants lived in the European country for less than nine years at the time of data collection (see Table 2). Nearly all participants were born in Iran and only $20 \%$ indicated being likely or very likely to return to Iran in the future. In terms of religious affiliation, more than one third of the participants indicated having none and around one third considered themselves to be Muslim.

\section{Measures}

\section{System Justification}

We used the general System Justification Scale (Kay \& Jost, 2003), adapted to the Western European country of residence, to assess the current level of system justification. This scale consists of eight items scored on a scale ranging from 1 (disagree completely) to 7 (agree completely). Examples of the items are "In general, I find society to be fair" and "In general, the [European country's] political system operates as it should”. Two items ("Society needs to be radically restructured" and "Our society is getting worse every year") were reverse scored. In each country, all items loaded on one factor. The reliability of the scale was good $(\alpha=.85$; range across countries $=.80-.87$ ). 
Table 2

Summary Statistics of the Sample of Iranian Migrants

\begin{tabular}{|c|c|c|}
\hline Variable name & $M(S D)$ & Percentage \\
\hline Gender (Female) & & 40.3 \\
\hline Age & $35.38(9.69)$ & \\
\hline \multicolumn{3}{|l|}{ Reason migration } \\
\hline Studies & & 39.5 \\
\hline Work & & 10.6 \\
\hline Political reasons & & 24.4 \\
\hline Family & & 14.1 \\
\hline Other & & 11.5 \\
\hline Years in [country] & $8.45(8.75)$ & \\
\hline Born in Iran & & 96.0 \\
\hline \multicolumn{3}{|l|}{ Legal Status } \\
\hline Permanent residency & & 43.9 \\
\hline Temporary residence: work or studies & & 31.0 \\
\hline Seeking asylum & & 14.1 \\
\hline \multicolumn{3}{|l|}{ Migrating back to Iran } \\
\hline (Very) Likely & & 20.0 \\
\hline Somewhat (un)likely/ neither unlikely nor likely & & 28.2 \\
\hline (Very) Unlikely & & 51.8 \\
\hline \multicolumn{3}{|l|}{ Subjective income } \\
\hline Living comfortably & & 30.4 \\
\hline Coping & & 40.5 \\
\hline Difficult & & 16.9 \\
\hline Very difficult & & 8.0 \\
\hline \multicolumn{3}{|l|}{ Education } \\
\hline $\mathrm{PhD}$ & & 35.4 \\
\hline Master & & 29.5 \\
\hline Bachelor & & 15.4 \\
\hline High School or lower & & 18.2 \\
\hline \multicolumn{3}{|l|}{ Religious Affiliation } \\
\hline Non-affiliated & & 36.8 \\
\hline Muslim & & 32.3 \\
\hline Christian & & 8.0 \\
\hline Other & & 7.1 \\
\hline Would rather not say & & 11.7 \\
\hline
\end{tabular}

\section{Political Orientation}

We used right-left self-placement as an indicator for political orientation, asking participants to place themselves on a scale ranging from 1 (right) to 10 (left): "In politics people sometimes talk of "left" and "right". Where would you place your views on this scale?" We reversed the endpoints of this specific scale in order to make it correspond to the visual location on the screen when completing the questionnaire in Farsi. 


\section{Efficacy}

We measured both individual and group political efficacy by asking participants to what extent "my participation in politics can have an impact on public policy in this country" and "organized groups of people can have an impact on public policy in this country”, respectively. We used a scale ranging from 1 (disagree completely) to 7 (agree completely).

\section{Perceived Stability}

Using the same 7-point scale, we included two items $(r=.43)$ to assess participants' perceived stability of the relations between different groups in society. The items were: "To what extent do you think that the differences between power and status between groups in [country] are difficult to change" and "To what extent do you think that the differences between power and status between groups in [country] will remain stable over time."

\section{Length of Residency}

We asked participants for how many years they have lived in the current European country that they live in.

\section{Disadvantage and Social Identity Threat}

First, on a 5-point scale (ranging from "disagree completely" to "agree completely"), we asked about the social status of Iranian migrants to assess respondents' perception of their ingroup's disadvantage: "I think Iranian migrants are disadvantaged in [country] society in terms of social status." Using the same scale, we also assessed respondents' experience of threat with statements representing different kinds of social identity threat (Branscombe et al., 1999). We measured categorization threat ("I think that [Europeans] see me first and foremost as a migrant" and "I think that most [Europeans] see me as an Arab migrant"), perceived cultural value threat ("I feel that my cultural values are not appreciated by [Europeans]"), realistic economic threat ("I often feel that as an Iranian migrant, it is harder to find a job in [country]"), and overt discrimination ("I often feel discriminated because of my Iranian background"). A different form of social identity threat for migrants is that they may not be accepted by other Iranian migrants, which we measured with the following item: "Other Iranian migrants do not consider me to be part of their group". Factor analysis in each country showed that despite the theoretical differences between these types of social identity threat, all but one item loaded on one factor. All items, except for being rejected by fellow Iranian migrants (ingroup threat), showed factor loadings above 0.50 in each country. We decided to create a scale for social identity threat based on all items except for ingroup threat. The reliability of this scale was sufficient $(\alpha=.77$; range between countries $=.72-.79)$.

\section{Social Identification}

We measured identity centrality (Cameron, 2004) on a scale ranging from 1 (disagree completely) to 5 (agree completely), asking participants to what extent being [European nationality], Iranian, or both [European nationality] and Iranian "are important parts of how I see myself." We adapted the European nationality for the different questionnaires in each country (e.g., German, Swedish).

\section{Political Participation Intentions}

To assess respondents' intentions to participate in political action, we asked how likely it was that they would vote, sign a petition, participate in a public demonstration, contact a politician, donate money for a political activity, or use violent forms of action with the goal of improving the position of Iranian migrants in the European country of residence. The scale ranged from 1 (very unlikely) to 7 (very likely). Earlier research already has shown that radical forms of political participation among migrants might differ from "legitimate" political action (Simon, Reichert, \& Grabow, 2013). Indeed, the different forms of political participation we measured loaded on one factor, except for the violent form of political action. Therefore, we created a scale based on the five other forms of political participation, which proved to be reliable $(\alpha=.85)$. 


\section{Control Variables}

We controlled for gender (dummy code: male, female), age, and education level obtained or currently enrolled in ( $\mathrm{PhD}$, Master, Bachelor, High School/Some degree or lower).

\section{Results}

With the various countries included in this study differing in terms of their sociopolitical system, we expected country level differences in the level of system justification. However, looking at the mean levels of system justification per country (see Table 3), we see that, with the exception of France and to a lesser extent Belgium, all six other countries show a relatively similar mean level of perceived fairness of the sociopolitical system. The average level of system justification among Iranian migrants is high compared to the average among native citizens that is typically reported in the literature. In an overview of studies using the same system justification scale, the ratio between the observed mean

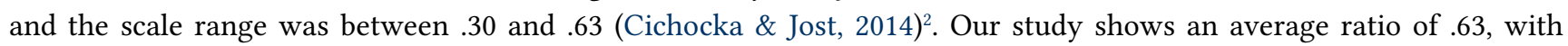
Switzerland scoring highest (.68) and France scoring lowest (.54). The latter is still high compared to previous findings, indicating that the Iranian migrants in our study generally perceive the system to be fair.

\section{Table 3}

Mean Levels of System Justification and Political Participation Intentions in Each Country

\begin{tabular}{lccc}
\hline & & System Justification & Political Participation Intentions \\
Country & $\boldsymbol{N}$ & $\boldsymbol{M}(\boldsymbol{S D})$ & $4.35(1.56)$ \\
\hline Austria & 95 & $4.55(1.11)$ & $4.55(1.50)$ \\
Belgium & 87 & $4.01(1.15)$ & $4.37(1.43)$ \\
Switzerland & 67 & $4.78(1.05)$ & $4.81(1.50)$ \\
France & 95 & $3.81(1.03)$ & $4.58(1.44)$ \\
Germany & 204 & $4.60(1.07)$ & $4.60(1.44)$ \\
Netherlands & 166 & $4.41(1.11)$ & $4.46(1.63)$ \\
United Kingdom & 107 & $4.29(1.16)$ & $4.49(1.52)$ \\
Sweden & 114 & $4.60(1.13)$ & $4.54(1.50)$ \\
Overall & 935 & $4.40(1.13)$ & \\
\hline
\end{tabular}

It is noteworthy that, on average, Iranian migrants in our sample consider themselves relatively left-wing politically $(M$ $=7.02, S D=2.53$, scale 1-10) and not very disadvantaged as a group $(M=2.62, S D=1.08$, scale $1-5$, see Table 4$)$. On the same 1-5 scale, they identify mostly as Iranian $(M=4.11, S D=1.05)$ rather than as European $(M=2.96, S D=1.21)$ or as having both identities $(M=3.55, S D=1.18)$.

The bivariate relations between system justification and its antecedents are generally weak. The largest correlations are between system justification and stability in intergroup relations, $r(935)=-.29, p<.001$, and social identity threat, $r(935)=-.34, p<.001$, suggesting that especially less stability and less experience of threat are associated with having more justification of the system. Despite the weak correlations, we note some interesting patterns in how people relate to the system. Identification with both Iranians and the native European population does not seem to be a 'risk' for system fairness perceptions, as signaled by a positive association with system justification, $r(935)=.16, p$ $<.001$. Identifying more strongly as Iranian is not significantly related to system justification, $r(935)=.06, p=.05$. Unsurprisingly, living in Europe for longer is related to stronger identification with the native European population,

2) We are aware that the ratio between the mean score and the range of the scale is not a completely accurate method to account for difference in scales. Nonetheless, with the majority of studies in the Cichocka and Jost (2014) overview using either 1-9 or 1-7 scales, we still consider the comparison between ratios meaningful. 
$r(917)=.19, p<.001$, but the experience of discrimination, $r(917)=-.07, p=.03$, and difficulties finding employment, $r(917)=-.10, p<.01$, do not seem to diminish substantially over time.

Table 4

Means and Correlations (Pairwise Deletion) of System Justification and All Predictor Variables

\begin{tabular}{|c|c|c|c|c|c|c|c|c|c|c|c|c|}
\hline Variable & $M(S D)$ & 1 & 2 & 3 & 4 & 5 & 6 & 7 & 8 & 9 & 10 & 11 \\
\hline 1. System Justification & $4.40(1.13)$ & - & & & & & & & & & & \\
\hline 2. Political Orientation & $7.02(2.53)$ & $-.09^{*}$ & - & & & & & & & & & \\
\hline 3. Individual Efficacy & $4.68(1.69)$ & $.23^{* * *}$ & .07 & - & & & & & & & & \\
\hline 4. Group Efficacy & $5.26(1.45)$ & $.20^{* * *}$ & $.15^{* * *}$ & $.61^{* * *}$ & - & & & & & & & \\
\hline 5. Stability & $3.94(1.18)$ & $-.29^{\star * *}$ & -.02 & $-.07^{*}$ & $-.09^{* *}$ & - & & & & & & \\
\hline 6. Years in [country] (1-36) & $8.45(8.75)$ & $-.12^{* * *}$ & -.07 & .03 & -.03 & $.09^{* *}$ & - & & & & & \\
\hline 7. Relative Disadvantage & $2.62(1.08)$ & $-.26^{* * *}$ & .02 & $-.12^{* * *}$ & $-.11^{* *}$ & $.15^{* * *}$ & $-.07^{*}$ & - & & & & \\
\hline 8. Social Identity Threat & $3.19(0.78)$ & $-.34^{* * *}$ & $.14^{* * *}$ & $-.08^{*}$ & -.06 & $.21^{* * *}$ & $-.08^{*}$ & $.38^{* * *}$ & - & & & \\
\hline 9. Ingroup Threat & $2.58(1.00)$ & $-.11^{* *}$ & -.04 & $-.08^{*}$ & -.06 & .06 & $-.12^{* * *}$ & $.15^{* * *}$ & $.25^{* * *}$ & - & & \\
\hline 10. Identification [Europeans] & $2.96(1.21)$ & $.17^{* * *}$ & $-.14^{* * *}$ & $.13^{* * *}$ & .01 & -.04 & $.19^{* * *}$ & $-.07^{*}$ & $-.10^{* *}$ & .01 & - & \\
\hline 11. Identification Iranians & $4.11(1.05)$ & .06 & -.06 & .02 & $.08^{*}$ & -.00 & -.06 & $-.06^{*}$ & $.13^{* * *}$ & -.01 & .03 & - \\
\hline 12. Dual Identification & $3.55(1.18)$ & $.16^{* * *}$ & $-.10^{\star *}$ & $.16^{* * *}$ & $.12^{* * *}$ & .01 & $.18^{* * *}$ & $-.13^{* * *}$ & -.06 & -.05 & $.58^{* * *}$ & $.31^{* * *}$ \\
\hline
\end{tabular}

Note. $N=935$, except for political orientation $(N=688)$ and numbers of years in Europe $(N=917)$. Scales: 1-7, except for political orientation $(1$, right 10, left), social identity threat, disadvantage, and identification (all 1-5).

${ }^{*} p<.05 .{ }^{* *} p<.01 .{ }^{* * *} p<.001$.

\section{Antecedents of System Justification}

To examine the predictors of system justification among Iranian migrants in Western-Europe, we conducted an Ordinary Least Squares (OLS) regression analysis with country dummies in all models and robust standard errors to account for differences in standard errors between the eight different countries (Gelman \& Hill, 2006; see Appendix 1 in the Supplementary Materials for the coefficients of the country dummies). In the first model, we included the known predictors of system justification (see Table 5). Next, we added the predictors specific to system justification among migrants, namely the number of years in the destination country and the different forms of threat and disadvantage (Model 2). The three different identification measures were added in Model 3 and in the final model we added gender, age, and education level as control variables. We found indications that the substantial number of missing observations on the political orientation measure $(n=247)$ was not missing completely at random ${ }^{3}$ (see Appendix 1 in the Supplementary Materials). Therefore, we conducted multiple imputation under the assumption of missing at random (following Poleto, Singer, \& Paulino, 2011; see Supplementary Materials (Appendix 2) for the complete case analysis that yields similar results).

The known predictors of system justification beliefs explain a substantial part of the variance in system justification among Iranian migrants. Between the different models, only the effect of stability in intergroup relations decreases substantially after adding the migrant specific predictors. In the final model, stronger right-wing political orientation was associated with stronger system justification $(B=-0.04, S E=0.02, p<.01)$, as well as higher individual $(B=$ $0.07, S E=0.03, p<.01)$ and group political efficacy $(B=0.07, S E=0.03, p=.02)$. Additionally, our expectation that opportunities for changes in society are associated with more favorable views of the system is supported by the findings that more stability in intergroup relations is related to less system justification $(B=-0.16, S E=0.03, p<.001)^{4}$.

3) Observations were mainly missing on the political orientation variable, meaning that the missing values are not missing completely at random. Because the source of missing values is known, they are not missing non-randomly either, which is why we conduct the analyses imputing data based in the assumption of missing at random.

4) The effect of stability was mainly driven by the item "differences in power and status between groups in [country] are difficult to change": when entered separately from the other stability item, this first item showed the negative relationship with system justification $(B=-0.19, S E=0.02, p<.001)$ whereas the item measuring whether the power and status differences between groups would remain stable over time, showed no significant relationship with system justification $(B=-0.03, S E=0.03, p=0.31)$. 


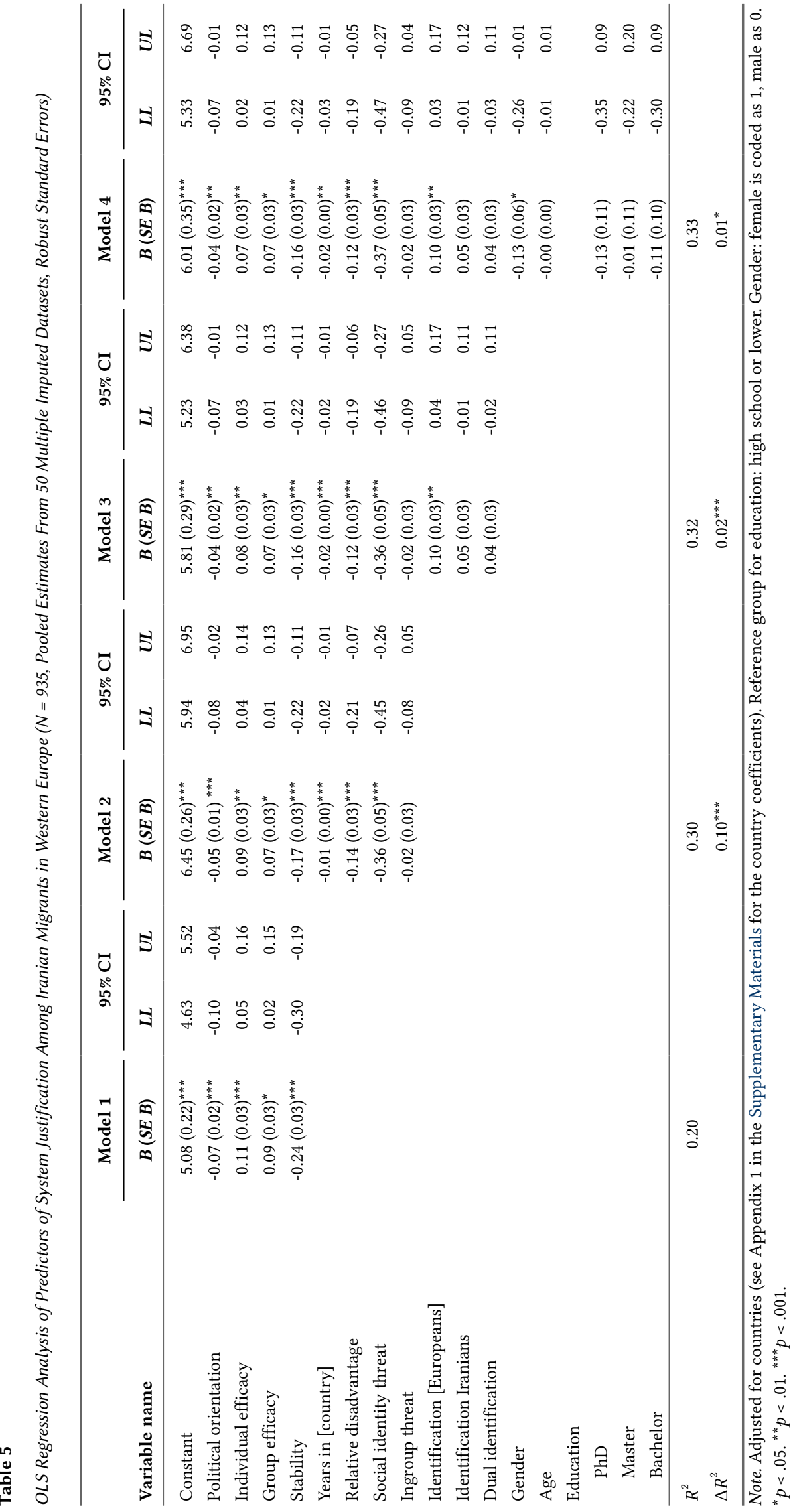


The social and political system is seen as fairer among Iranian migrants who migrated to their current European country of residence more recently $(B=-0.02, S E=0.005, p=.001)$. Feeling disadvantaged as an Iranian migrant $(B=$ $-0.12, S E=0.03, p<.001)$ and social identity threat $(B=-0.37, S E=0.05, p<.001)$ relate negatively to system justification. Ingroup threat $(B=-0.02, S E=0.03, p=.48)$ does not relate to system justification. The different migrant specific factors together explain an additional $10 \%$ of the variance in system justification and the effects do not differ markedly between models two and four.

We found support for our expectation that identification with the native European population contributes to system justification $(B=0.10, S E=0.03, p<.01)$, and it is noteworthy that identification with Iranians did not decrease system justification $(B=0.05, S E=0.03, p=.11)$. Finally, adding the control variables did not bring about substantial changes in the effects of the other predictors.

\section{System Justification and Political (In)Action}

The zero-order correlation between system justification and intentions to engage in political action to improve the position of Iranian migrants is close to zero, $r(933)=.04, p=.21$. Hence unsurprisingly, a regression analysis with robust standard errors $(N=921)$ also shows that system justification was not associated with political participation intentions ( $b=0.07, p=.15$ ), adjusted for age, gender, education level, and the country of residence. However, including the quadratic term for system justification reveals a curvilinear effect of system justification on political participation intentions (see Figure 1). Higher system justification is associated with increased political participation intentions $(b=$ $0.68, p=.01$ ) but these intentions decrease when system justification is too high (squared term, $b=-0.07, p=.02$; see Table 6). These findings support the previously obtained curvilinear effect of system justification on political participation (Cichocka et al., 2018). However, the effects we observed are very small in size, the total model including the control variables explains around $2 \%$ of the variance in political participation intentions.

Figure 1

Intentions for Political Participation Among Iranian Migrants in Western Europe as a Function of System Justification (Other Variables Kept Constant at Their Mean)

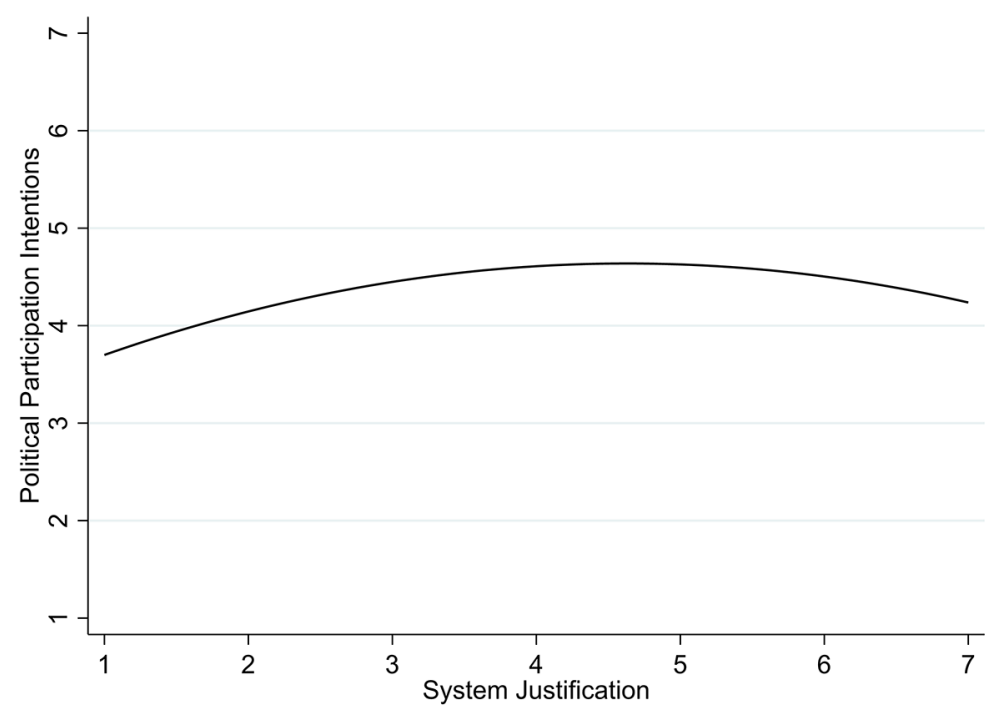


Table 6

Regression Analysis of Political Participation Intentions Among Iranian Migrants in Western Europe (N=921, Robust Standard Errors)

\begin{tabular}{lc}
\hline & Model \\
Variable name & $\boldsymbol{B}(\boldsymbol{S E} \boldsymbol{B})$ \\
\hline Constant & $2.84(0.61)^{* * *}$ \\
System justification & $0.68(0.27)^{*}$ \\
System justification squared & $-0.07(0.03)^{*}$ \\
Gender & $-0.13(0.10)$ \\
Age & $0.01(0.01)$ \\
Education & \\
$\quad$ PhD & $-0.13(0.17)$ \\
$\quad$ Master & $0.01(0.15)$ \\
\hline$R^{2}$ & $-0.01(0.14)$ \\
\hline
\end{tabular}

Note. Adjusted for countries. Reference group for education: high school or lower. Gender: female is coded as 1, male as 0.

${ }^{a}$ ref: high school or lower.

${ }^{*} p<.05 .{ }^{* *} p<.01 .{ }^{* * *} p<.001$.

\section{Discussion}

In this research, we examined the factors that play a role in the extent to which Iranian migrants see the sociopolitical system of the Western European country they migrated to as fair. We argued that the level of system justification for migrants can be an outcome of a motivated process of inflating the fairness of the system, but can also be shaped by their possible experiences of discrimination and disadvantage, and their relation to the new country of residence. We found that, on average, the highly educated group of Iranian migrants in our sample showed relatively high levels of system justification. However, feeling disadvantaged relative to the native European population, experiencing social identity threat, a lack of political influence, and general perceived stability in intergroup relations all decreased the fairness of the system. Overall, there was a lower level of system justification among Iranian migrants who resided in the European country for longer. In line with the association between system justification and conservatism (e.g., Jost, Glaser, et al., 2003), we found that political right-wing orientation was related to stronger system justification. Finally, we found support for the curvilinear association between system justification and political participation intentions (Cichocka et al., 2018), with both very high and very low levels of system justification making political participation less likely. However, system justification only seems to play a minor role in political participation intentions of Iranian migrants in Western-Europe.

An important limitation to our study is that with the cross-sectional design, we cannot draw any firm conclusions about the causal influence of the predictors of system justification that our study included. Previous research suggests that justification of the system can be a way to cope with uncertainty and threat (e.g., Lau et al., 2008) but especially for migrants, it is conceivable that discrimination or disadvantage are at least partially blamed on an unfair system. Despite the lack of causal inference, we think that assessing the level of system justification in itself is important. Banfield, Kay, Cutright, Wu, and Fitzsimons (2011) showed that only people who have low levels of system confidence are more likely to justify the system in response to threat. The high level of system justification among Iranian migrants in our study shows that currently there is little room to inflate the fairness of the system even more. This could imply that other forms of coping with threat might be needed when Iranian migrants experience additional difficulties in society. Experiences of discrimination could, for example, also be downplayed by Iranian migrants as a form of emotion-focused coping with the long-term risk of increased depressive symptoms (see for example Noh \& Kaspar, 2003). Additionally, disidentification from the Iranian migrant ingroup could be used a form of individual mobility (e.g., Bobowik, Martinovic, Basabe, Barsties, \& Wachter, 2017). An obvious avenue for further investigation 
of these possibilities is to experimentally test the influence of the different social identity threats we measured, and possibly compare the process of system justification between short- and long-term migrants. It seems plausible that for short-term migrants, experiences of discrimination or not being accepted into a community have less impact on their general perceptions of the host system. Conversely, long-term migrants might be affected more by these threats and might need additional coping strategies.

We found that system justification decreased slightly when the length of residence in Western Europe increased. Nearly all the participants in our study were born in Iran, indicating that the decrease in system justification is not caused by a difference in being first- or second-generation migrant, and there is no clear indication in our data that recent migration was driven by different factors compared to migration several decades ago. Therefore, we think that the higher levels of system justification among recent migrants - similar to research on political trust (Michelson, 2003) - can be partially ascribed to contrasting the current system to Iran's system and possibly rationalizing the act of migrating to another country. Adding to research on political trust, however, system justification captures a broader fairness perception of both the social and political system. This is signaled by our finding that for Iranian migrants who have lived in Europe longer, identification with Europeans increases, but at the same time difficulties with finding employment and experiencing discrimination-inhibiting system justification-remain.

Our study provides one of the first assessments of how system justification among migrants is shaped and caution is needed in generalizing these findings. The Iranian migrants in our sample were mostly young and highly educated. Migration can be motivated by vastly different factors. For refugees escaping political violence or for people migrating to a neighboring European country for a job, the psychology of migrating will be immensely different. For the latter, cultural differences, for example, might be so small that they do not play a profound role in system justification. To better understand how the system fairness perceptions of migrants are shaped, future endeavors should focus on comparing different groups of migrants, ideally using representative samples. The antecedents of system justification that we studied can provide a general framework for these future studies, to which factors stemming from the idiosyncrasies of each specific group of migrants can be added. Moreover, future research could consider that some antecedents might have non-linear effects on system justification. An exploratory analysis suggests that there are curvilinear relationships between system justification and the number of years that Iranian migrants have lived in Europe, perceptions of intergroup stability, and political ideology (see Appendix 3, Supplementary Materials). Additionally, different consequences of system justification can be taken into account. We found that, although we replicated the curvilinear effect of system justification on political participation intentions (Cichocka et al., 2018), system justification seems to play only a very minor role in Iranian migrants' political participation. Different outcomes of increased system justification should therefore be considered in future research as well, for example involvement in civil society. Finally, future research should focus on which parts of the system are most salient for immigrants compared to native citizens of a country. Earlier research has shown that immigrants in the United States of America are most likely to justify economic aspects of the American system compared to the social aspects of the system (Feygina \& Godfrey, 2018). Depending on the reason for which people migrate and the country to which they migrate, different aspects of the system are justified more strongly compared to other aspects.

In an increasingly globalized world, it is important to understand legitimacy and fairness perceptions of a system among all inhabitants of a country. As a first inquiry into the system justification of migrants, we think that our study provides an important initial step in understanding how both group and system level factors play a role in the psychology of being a migrant. The specific challenges and strain related to being a migrant might be blamed on the sociopolitical system, but the experience of opportunity after moving to a new country can contribute to fairness perceptions of the new country of residence. 
Funding: The non-governmental organization the Simorgh in Austria has provided funding for advertising this study online. They were not involved in the design, analyses, or reporting on this study.

Acknowledgments: We would like to thank John Jost, Irina Feygina, Aleksandra Cichocka, Russell Spears, Pari Namazie, and Bert Klandermans for their help in designing this study and/or providing help with interpreting and reporting on the findings. We thank everyone who has helped in distributing the survey. Finally, we are grateful to Pamela Massoudi, Alexander Schwartz, Afsaneh Gächter, Darya Moghimi, and Julia Sasse for helping us with the translation of the questionnaires.

Competing Interests: The authors have declared that no competing interests exist.

Data Availability: The full data are available upon reasonable request considering privacy restrictions.

\section{Supplementary Materials}

All the materials for this study are added as supplementary materials. All relevant descriptive data are reported in the article. The Supplementary Materials contain four appendices. In the first appendix, a missing values analysis and the country coefficients for the regression analysis in the main text can be found. Appendix 2 contains the regression analysis without imputed values. In Appendix 3, several quadratic relations of system justification's antecedents are explored. The full questionnaire used for this study can be found in Appendix 4 (for access see Index of Supplementary Materials below).

\section{Index of Supplementary Materials}

van Bezouw, M. J., van der Toorn, J., Honari, A., \& Rijken, A. J. (2021). Supplementary materials to "Antecedents and consequences of system justification among Iranian migrants in Western Europe" [Appendices]. PsychOpen GOLD.

https://doi.org/10.23668/psycharchives.5246

\section{References}

Abrajano, M. A., \& Alvarez, R. M. (2010). Assessing the causes and effects of political trust among US Latinos. American Politics Research, 38(1), 110-141. https://doi.org/10.1177/1532673X08330273

Ayanian, A. H., \& Tausch, N. (2016). How risk perception shapes collective action intentions in repressive contexts: A study of Egyptian activists during the 2013 post-coup uprising. British fournal of Social Psychology, 55(4), 700-721.

https://doi.org/10.1111/bjso.12164

Banfield, J. C., Kay, A. C., Cutright, K. M., Wu, E. C., \& Fitzsimons, G. J. (2011). A person by situation account of motivated system defense. Social Psychological \& Personality Science, 2(2), 212-219. https://doi.org/10.1177/1948550610386809

Barreto, M., Spears, R., Ellemers, N., \& Shahinper, K. (2003). Who wants to know? The effect of audience on identity expression among minority group members. British fournal of Social Psychology, 42(2), 299-318. https://doi.org/10.1348/014466603322127265

Behrooz, M. (2012). Iran after Revolution (1979-2009). In T. Daryaee (Ed.), The Oxford handbook of Iranian history (pp. 365-389). New York, NY, USA: Oxford University Press.

Bilodeau, A., \& Nevitte, N. (2003). Political trust for a new regime: The case of immigrants from non-democratic countries in Canada. Paper presented at the Annual Meeting of the Canadian Political Science Association, Halifax, NS, Canada.

Bobowik, M., Martinovic, B., Basabe, N., Barsties, L. S., \& Wachter, G. (2017). 'Healthy' identities? Revisiting rejection-identification and rejection-disidentification models among voluntary and forced immigrants. European fournal of Social Psychology, 47(7), 818-831. https://doi.org/10.1002/ejsp.2306

Branscombe, N. R., Ellemers, N., Spears, R., \& Doosje, B. (1999). The context and content of social identity threat. In B. Doosje, N. Ellemers, \& R. Spears (Eds.), Social identity: Context, commitment, content (pp. 35-58). Oxford, United Kingdom: Blackwell Science.

Cameron, J. E. (2004). A three-factor model of social identity. Self and Identity, 3(3), 239-262.

https://doi.org/10.1080/13576500444000047 
Cichocka, A., Górska, P., Jost, J. T., Sutton, R. M., \& Bilewicz, M. (2018). What inverted U can do for your country: A curvilinear relationship between confidence in the social system and political engagement. fournal of Personality and Social Psychology, 115(5), 883-902. https://doi.org/10.1037/pspp0000168

Cichocka, A., \& Jost, J. T. (2014). Stripped of illusions? Exploring system justification processes in capitalist and post-Communist societies. International fournal of Psychology, 49(1), 6-29. https://doi.org/10.1002/ijop.12011

Day, M. V., \& Fiske, S. T. (2017). Movin'on up? How perceptions of social mobility affect our willingness to defend the system. Social Psychological \& Personality Science, 8(3), 267-274. https://doi.org/10.1177/1948550616678454

Faul, F., Erdfelder, E., Buchner, A., \& Lang, A. G. (2009). Statistical power analyses using G*Power 3.1: Tests for correlation and regression analyses. Behavior Research Methods, 41(4), 1149-1160. https://doi.org/10.3758/BRM.41.4.1149

Feygina, I., \& Godfrey, E. (2018). Paying the price for the American Dream? The role of system justification in ethnic group evaluation and well-being among immigrants [Unpublished manuscript]. Change Institute.

Gelman, A., \& Hill, J. (2006). Data analysis using regression and multilevel/hierarchical models. New York, NY, USA: Cambridge University Press.

Ghorashi, H. (2003). Ways to survive, battles to win: Iranian women exiles in the Netherlands and United States. Hauppauge, NY, USA: Nova Science.

Ghorashi, H., \& Boersma, F. K. (2009). Iranian diaspora and the new media: From political action to humanitarian help. Development and Change, 40(4), 667-691. https://doi.org/10.1111/j.1467-7660.2009.01567.x

Henry, P. J., \& Saul, A. (2006). The development of system justification in the developing world. Social fustice Research, 19(3), 365-378. https://doi.org/10.1007/s11211-006-0012-x

Honari, A. (2018). "We will either find a way, or make one": How Iranian green movement online activists perceive and respond to repression. Social Media + Society, 4(3), 1-11. https://doi.org/10.1177/2056305118803886

Jost, J. T., \& Banaji, M. R. (1994). The role of stereotyping in system-justification and the production of false consciousness. British Journal of Social Psychology, 33(1), 1-27. https://doi.org/10.1111/j.2044-8309.1994.tb01008.x

Jost, J. T., Banaji, M. R., \& Nosek, B. A. (2004). A decade of system justification theory: Accumulated evidence of conscious and unconscious bolstering of the status quo. Political Psychology, 25(6), 881-919. https://doi.org/10.1111/j.1467-9221.2004.00402.x

Jost, J. T., Glaser, J., Kruglanski, A. W., \& Sulloway, F. J. (2003). Political conservatism as motivated social cognition. Psychological Bulletin, 129(3), 339-375. https://doi.org/10.1037/0033-2909.129.3.339

Jost, J. T., Langer, M., Badaan, V., Azevedo, F., Etchezahar, E., Ungaretti, J., \& Hennes, E. P. (2017). Ideology and the limits of selfinterest: System justification motivation and conservative advantages in mass politics. Translational Issues in Psychological Science, 3(3), e1-e26. https://doi.org/10.1037/tps0000127

Jost, J. T., Pelham, B. W., Sheldon, O., \& Sullivan, B. N. (2003). Social inequality and the reduction of ideological dissonance on behalf of the system: Evidence of enhanced system justification among the disadvantaged. European fournal of Social Psychology, 33(1), 13-36. https://doi.org/10.1002/ejsp.127

Jost, J. T., \& Van der Toorn, J. (2012). System justification theory. In P. A. M. van Lange, A. W. Kruglanski, \& E. T. Higgins (Eds.), Handbook of theories of social psychology (pp. 313-343). London, United Kingdom: SAGE.

Kay, A. C., \& Jost, J. T. (2003). Complementary justice: Effects of "poor but happy" and "poor but honest" stereotype exemplars on system justification and implicit activation of the justice motive. fournal of Personality and Social Psychology, 85(5), 823-837. https://doi.org/10.1037/0022-3514.85.5.823

Kelly, M., \& Hedman, L. (2016). Between opportunity and constraint: Understanding the onward migration of highly educated Iranian refugees from Sweden. Fournal of International Migration and Integration, 17(3), 649-667. https://doi.org/10.1007/s12134-015-0422-4

Lau, G. P., Kay, A. C., \& Spencer, S. J. (2008). Loving those who justify inequality: The effects of system threat on attraction to women who embody benevolent sexist ideals. Psychological Science, 19(1), 20-21. https://doi.org/10.1111/j.1467-9280.2008.02040.x

Laurin, K., Gaucher, D., \& Kay, A. (2013). Stability and the justification of social inequality. European fournal of Social Psychology, 43(4), 246-254. https://doi.org/10.1002/ejsp.1949

Lewin, F. A. (2001). Identity crisis and integration: The divergent attitudes of Iranian immigrant men and women towards integration into Swedish society. International Migration, 39(3), 121-135. https://doi.org/10.1111/1468-2435.00159

Major, B., Kaiser, C. R., O’Brien, L. T., \& McCoy, S. K. (2007). Perceived discrimination as worldview threat or worldview confirmation: Implications for self-esteem. Journal of Personality and Social Psychology, 92(6), 1068-1086.

https://doi.org/10.1037/0022-3514.92.6.1068 
Michelson, M. R. (2003). The corrosive effect of acculturation: How Mexican Americans lose political trust. Social Science Quarterly, 84(4), 918-933. https://doi.org/10.1046/j.0038-4941.2003.08404017.x

Morady, F. (2011). Who rules Iran? The June 2009 election and political turmoil. Capital and Class, 35(1), 39-61. https://doi.org/10.1177/0309816810393940

Newton, K., Stolle, D., \& Zmerli, S. (1999). Social and political trust. In E. M. Uslaner (Ed.), The Oxford handbook of social and political trust (pp. 37-56). Oxford, United Kingdom: Oxford University Press.

Noh, S., \& Kaspar, V. (2003). Perceived discrimination and depression: Moderating effects of coping, acculturation, and ethnic support. American fournal of Public Health, 93(2), 232-238. https://doi.org/10.2105/AJPH.93.2.232

Norris, P. (2011). Democratic deficit: Critical citizens revisited. Cambridge, United Kingdom: Cambridge University Press.

Osborne, D., Yogeeswaran, K., \& Sibley, C. G. (2015). Hidden consequences of political efficacy: Testing an efficacy-apathy model of political mobilization. Cultural Diversity \& Ethnic Minority Psychology, 21(4), 533-540. https://doi.org/10.1037/cdp0000029

Poleto, F. Z., Singer, J. M., \& Paulino, C. D. (2011). Missing data mechanisms and their implications on the analysis of categorical data. Statistics and Computing, 21(1), 31-43. https://doi.org/10.1007/s11222-009-9143-x

Simon, B., Reichert, F., \& Grabow, O. (2013). When dual identity becomes a liability: Identity and political radicalism among migrants. Psychological Science, 24(3), 251-257. https://doi.org/10.1177/0956797612450889

Van den Bos, M. (2006). Hyperlinked Dutch-Iranian Cyberspace. International Sociology, 21(1), 83-99. https://doi.org/10.1177/0268580906059292

Van der Toorn, J., Feinberg, M., Jost, J. T., Kay, A. C., Tyler, T. R., Willer, R., \& Wilmuth, C. (2015). A sense of powerlessness fosters system justification: Implications for the legitimation of authority, hierarchy, and government. Political Psychology, 36(1), 93-110. https://doi.org/10.1111/pops.12183

Verkuyten, M. (2006). Multicultural recognition and ethnic minority rights: A social identity perspective. European Review of Social Psychology, 17(1), 148-184. https://doi.org/10.1080/10463280600937418

Verkuyten, M., \& Martinovic, B. (2012). Social identity complexity and immigrants' attitude toward the host nation: The intersection of ethnic and religious group identification. Personality and Social Psychology Bulletin, 38(9), 1165-1177.

https://doi.org/10.1177/0146167212446164

Wiley, S. (2013). Rejection-identification among Latino immigrants in the United States. International fournal of Intercultural Relations, 37(3), 375-384. https://doi.org/10.1016/j.ijintrel.2012.08.018 